\title{
Commercial versus synthesized polymers for soil erosion control and growth of Chinese cabbage
}

\author{
Sang Soo Lee', Scott X Chang ${ }^{2}$, Yoon-Young Chang ${ }^{3}$ and Yong Sik Ok ${ }^{{ }^{*}}$
}

\begin{abstract}
Soil erosion leads to environmental degradation and reduces soil productivity. The use of anionic polyacrylamide (PAM) and synthesized biopolymer (BP) using lignin, corn starch, acrylamide, and acrylic acid were tested to evaluate soil erosion, water quality, and growth of Chinese cabbage (Brassica campestris L.). Each treatment of PAM and BP was applied at $200 \mathrm{~kg} \mathrm{ha}^{-1}$ to loamy sand soil and subjected to a slope of $36 \%$ with a $20 \mathrm{~mm} \mathrm{~h}^{-1}$ simulated rainfall. Application of BP decreased soil pH compared to the untreated check (CK); however, the soil $\mathrm{pH}$ was not altered with PAM. The decrease in $\mathrm{pH}$ might most likely be due to availability of anionic sites to be protonated on soils having $\mathrm{pH}>6$ and soil buffering capacity. Both PAM and BP applications may not induce eutrophication with stable levels of total contents of $\mathrm{N}$ and $\mathrm{P}$. With PAM and BP, the average values of suspended soil (SS) and turbidity were reduced by up to 96.0 and 99.9\%, respectively, compared to CK. Reduction of SS can be attributed to increasing soil stability and shear strength by clay flocculation. There was no toxicity effects resulting from germination tests and the dry weight was increased by $17.7 \%$ (vs. CK) when PAM and BP were applied. These results are attributed to increases in water retention and plant-available water. The use of polymeric soil amendments is an environmentally friendly way to mitigate soil erosion and nonpoint source pollution.
\end{abstract}

Keywords: Biopolymer; Erosion control; Plant growth; Polyacrylamide; Water quality

\section{Introduction}

Soil erosion is a natural process resulting primarily from forces of water and wind. Soil particles are detached from soil aggregates and moved to other locations by natural processes (McIntyre 1958; Troeh et al. 2004). Many factors such as the slope, soil properties, rainfall intensity, and management practices directly affect the yield of soil erosion or its acceleration rate (Agassi et al. 1990; Gerits 1990; Kinnell 2000; Troeh et al. 2004).

The slope is one of the most important factors determining the characteristics of soil erosion, particularly in highland areas which are located at $600 \mathrm{~m}$ above sea level (Agassi and Ben-Hur 1992; Polyakov and Lal 2004; Heo et al. 2008; Lee et al. 2011). Soil erosion can be multiplied without vegetation cover mainly due to the

\footnotetext{
* Correspondence: soilok@kangwon.ac.kr

${ }^{1}$ Department of Biological Environment, Kangwon National University,

Chuncheon 200-701, Korea

Full list of author information is available at the end of the article
}

impacts of gradient (Kinnell 2000; WSDOT 2008). Many studies have shown that an increasing slope intensifies soil erosion, resulting from decreasing water infiltration rate, reducing potential of water ponding, and increasing velocity of surface water flow (Agassi et al. 1990; Bradford and Foster 1996; Fox and Bryan 1999). Therefore, soil erosion control in highland areas has received great attention. In Korea, the cultivable highland areas occupies greater than $10.4 \%$ of the total upland area or approximately $7.4 \times 10^{4}$ ha (Partab 2004). Due to a high potential of soil erosion and a low temperature condition in highlands, a very limited number of plant species is being cultivated such as Chinese cabbage (Brassica campestris L.) and radish (Raphanus sativus) (Jung et al. 2005).

Soil erosion also causes nonpoint source pollution severely degrading water quality and aquatic ecosystems (Gantzer et al. 1990; Thompson et al. 1991; Mikkelsen 1994; Pimentel et al. 1995; Nagle 2001). Nonpoint source pollution induces exceed transportation of organic/inorganic nutrient chemicals from agricultural 
fields, thereby inducing eutrophication in aquatic systems and subsequent environmental devastation (Clark et al. 1985; Myers 1993; Choi et al. 2000; USEPA 2004; Shin 2006). Consequently, it threatens agricultural sustainability and requires enormous restoration costs (Clark et al. 1985).

Many conservative structures have been widely constructed to mitigate detrimental damages of soil erosion using natural or artificial materials (Nagle 2001; Lentz and Sojka 2009). At agricultural fields, the best management practices (BMPs) including mulches, vegetative buffer strips, contour farming, grassland formation, perennial plant cultivation, no-till cultivation, cover crops etc. were suggested (Troeh et al. 2004; Yang et al. 2006). Since the 1990s, the application of polymeric soil amendments has been known as one of the BMPs by many researchers and governmental institutes (Sojka et al. 2007; WSDOT 2008).

Anionic polyacrylamide (PAM) as a representative is an environment-friendly polymeric soil amendment for controlling soil erosion and runoff in the United States and Canada (Entry et al. 2002; Lentz et al. 2002; Al-Abed et al. 2003). The PAM refers to a broad class of compounds having a high molecular weight of $12-15 \mathrm{Mg}$ $\mathrm{mol}^{-1}$ and functional group substitutions with different formations (Sojka et al. 2007). Charge density of PAM is typically $18 \%$. Several hundred types have been synthesized with different types, numbers, and lengths of functional groups (Shainberg and Levy 1994; Entry et al. 2002). It should be noted that an anionic form of PAM is widely used because of its lower toxicity compared to other forms (Shainberg and Levy 1994; Flanagan et al. 1997; Sojka et al. 2007). PAMs contain less than $0.05 \%$ residual acrylamide monomer (AMD) for humans or aquatic species safety. For the economic aspect, the total cost of PAM application can be recovered by profit of increasing crop yield. Total cost of PAM application may reach to \$106 USD ha ${ }^{-1} \mathrm{y}^{-1}$ (\$9.90 $\mathrm{kg}^{-1}$ PAM); however, the yields of bean and corn were increased by 12.3 and $4.8 \%$, respectively, for a PAM-treated field compared to an untreated field. Lentz and Sojka (2009) insisted that increases of crop yield were sufficient to countervail PAM application expense.

Surface application of PAM to soil alters soil structure via clay flocculation (Quastel 1954; Orts et al. 1999, 2007). Calcium as one of the electrolytes reduces the diffuse double layer surrounding soil particles and facilitates the bridging between soil particles and PAM molecules (Theng 1982; Fuller et al. 1995; Orts et al. 2000; Entry et al. 2002). The application of PAM has been known to stabilize soil aggregates (Sojka et al. 2007), improve soil aeration (Quastel 1952; Lee et al. 2008), and increase water permeability or infiltration (Mitchell 1986). McElhiney and Osterli (1996) found that the infiltration rate increased by up to $40 \%$ in sandy loam soils when a $0.01 \%$ PAM solution was applied. The use of PAM also reduces water turbidity and increases its quality (Flanagan et al. 1997; Ajwa and Trout 2006). For the PAM application in the fields having a relatively high slope, it has been known as an effective way to control soil erosion. Agassi and Ben-Hur (1992) conducted an erosion experiment using PAM and phosphogypsum (a source of $\mathrm{Ca}^{2+}$ as an electrolyte). They found that a combination of $20 \mathrm{~kg} \mathrm{ha}^{-1}$ PAM with $10 \mathrm{Mg} \mathrm{ha}^{-1}$ phosphogypsum was very effective in erosion control on steep slopes ranging from 30 to $60 \%$. Sepaskhah and Bazrafshan-Jahromi (2006) showed that a $4 \mathrm{~kg} \mathrm{ha}^{-1}$ PAM application may be sufficient in controlling soil loss on loam soils with relatively flat slopes of $5-7.5 \%$. Otherwise, a study of Lee et al. (2011) suggested that the amount of applied PAM should be increased as the slope increases for efficient soil erosion control. They found that application of $40 \mathrm{~kg} \mathrm{ha}^{-1}$ PAM on $40 \%$ sloping soils reduced soil erosion by up to $72 \%$ compared to the untreated soil. A higher amount of PAM may be more effective in reducing soil erosion than a lower rate of PAM at $\geq 20 \%$ slopes.

Polymeric soil amendments increase seed germination. Chan and Sivapragasam (1996) found that PAM application at a rate of $7 \mathrm{~kg} \mathrm{ha}^{-1}$ improved cotton germination rate by up to $84 \%$. Sivapalan (2002) conducted a similar pot experiment using cotton seeds subjected to different rates of PAM at $0,0.001,0.005$, and $0.01 \%$ by dry soil weight of Alfisol. They found that PAM increased seed germination through reducing soil penetration resistance. Seed germination also can be improved through the prevention of washing-away, and stimulation of seedling emergence or sward establishment (Roa-Espinosa 1996; Roa-Espinosa et al. 1999; Sojka et al. 2003).

Under drought or no irrigation condition, an increase of plant growth on the soils treated with PAM has been reported, mainly due to increasing plant-available water in soils (Johnson Johnson 1984a, 1984b; Cook and Nelson 1986; Woodhouse and Johnson 1991; Hüttermann et al. 1999; Sharma 2004). Studies of Johnson (1984a, 1984b) and Woodhouse and Johnson (1991) also showed an increase in plant-available water when applied PAM or starch copolymer with sufficient electrolytes. Woodhouse and Johnson (1991) revealed that the use of starch copolymers increased growth rates of lettuce and barley, and improved plant survival in a silica sand during a drought period. Hüttermann et al. (1999) supported their studies and found that Aleppo pine (Pinus halepensis) seedlings survived up to $82 \mathrm{~d}$ with PAM application. It was $33 \mathrm{~d}$ longer than the untreated soils. They explained that soil water retention increased exponentially with increasing concentrations of super absorbent hydrogel (Stockosorb K400) which indicates a 
cross-linked form. Ghehsareh et al. (2010) also found that soil water retention was increased with a $1 \%$ superabsorbent polymer (superab-A 200), thereby improving the growth rate of Ficus tree (Ficus benjamina L. 'Starlight').

More recently, a synthesized biopolymer (BP) was recognized as an alternative to conventional chemical-based tackifiers such as PAM. Natural and industrial byproducts may be sources of BPs synthesis (Sojka et al. 2007; Liu et al. 2008). The BPs provide a cost advantage and an additional safety to environments by using natural and non-toxic materials such as lignin, starch, sugar, cellulose etc. (Parker and Ring 2005; Sojka et al. 2005, 2007). Woodhouse and Johnson (1991) partially insisted that the effects of BPs on plant growth would be similar or better than the use of PAM. However, the effectiveness of BP for soil erosion control and its safety have not been clearly defined relative to that of PAM. Therefore, the objective of this study was to evaluate the effectiveness of PAM and BP applications on soil erosion control, water quality enhancement, and growth stimulation of Chinese cabbage.

\section{Materials and methods}

\section{Soil}

Soil was collected from the surface to a depth of $30 \mathrm{~cm}$ after eliminating vegetation in Haean-myeon, Yanggugun, Gangwon province, Korea $\left(38^{\circ} 15^{\prime} 54^{\prime \prime} \mathrm{N}\right.$ lat., $128^{\circ} 07^{\prime} 02^{\prime \prime} \mathrm{E}$ long.). The properties of soil are shown in Table 1. The soil was air dried and passed through a 2-mm sieve. Soil $\mathrm{pH}$ and EC were measured with a solution of 1:5 soil:water (Orion 3 Star, Thermo, USA). Soil aggregate stability and water retention were determined using an aggregate analyzer (DIK-2001, Daiki Rika Kogyo, Japan) and a pressure membrane extractor (1500F1, Soil Moisture Equipment Corp., USA), respectively (RDANIAST 1988). The organic matter (OM) content was determined by the Walkley Black method using an ultraviolet absorption spectrophotometer (UV-1800, Shimadzu, Japan), and the available phosphorus were analyzed at wavelengths of 610 and $660 \mathrm{~nm}$ by the Kjeldahl and molybdenum blue colorimetric methods, respectively (Bremner 1996; Kuo 1996; Nelson and Sommers 1996;
Yoon et al. 2004). Contents of inorganic $\mathrm{N}$ were analyzed using an ion analyzer after $2-\mathrm{mol} \mathrm{L}^{-1}$ potassium chloride extraction. Exchangeable cations were determined with a $1 \mathrm{~N}$ ammonium acetate $\left(\mathrm{NH}_{4} \mathrm{OAc}\right)$ solution using inductively coupled plasma (ICP) (Sumner and Miller 1996; Ok et al. 2007). Additionally, the soil particle distribution was determined using the hydrometer method by Sheldrick and Wang (1993). Soil characterization was triplicated and the measurements of soil aggregate stability and water retention were done with five replicates.

\section{Polyacrylamide and synthesized biopolymer}

A commercial Soilfix G1 anionic PAM (Ciba Chemical Co., Germany) and a synthesized BP based on lignin, corn starch, acrylamide, and acrylic acid were used in this study. Characterization of the properties of each treatment were triplicated and shown in Table 1. To synthesize BP, a total of 4-g lignin, 0.4-g corn starch, and 16-g acrylamide were completely homogenized with 100 $\mathrm{mL}$ of distilled water having an electrical conductivity (EC) of $4.17 \times 10^{-4} \mathrm{~S} \mathrm{~m}^{-1}$ and $\mathrm{pH}$ of 7.2 , and then $12-\mathrm{mL}$ acrylic acid was added (Liu et al. 2008). The solution $\mathrm{pH}$ was adjusted to 7.5 by adding sodium hydroxide $(\mathrm{NaOH})$ and was dissolved with $200 \mathrm{~mL}$ of distilled water. At a temperature of $70^{\circ} \mathrm{C}, 1.2 \mathrm{~g}$ of potassium persulfate $\left(\mathrm{K}_{2} \mathrm{~S}_{2} \mathrm{O}_{8}\right)$ was added after 30 -min stirring for the radical polymerization reaction. The $\mathrm{BP}$ was extracted using acetone $\left(\left(\mathrm{CH}_{3}\right)_{2} \mathrm{CO}\right)$ and then dried at a temperature of $60^{\circ} \mathrm{C}$. A granular type of synthesized BP was ground using a laboratory cutting mill (Ika M20 Labortechnik Staufen, Germany). Total nitrogen and carbon (TC) were analyzed using an elemental analyzer (Carlo Erba 1500, Carlo Erba Instruments, Italy).

\section{Simulated rainfall experiment}

Soil was repacked into soil test beds $(40-\mathrm{mm}$ wide by 443-mm long by $78-\mathrm{mm}$ deep) with a bulk density of $1.1 \mathrm{Mg} \mathrm{m}^{-3}$. Each $200 \mathrm{~kg} \mathrm{ha}^{-1}$ (or $0.35 \mathrm{~g}$ ) of PAM and BP was dissolved with 500-mL distilled water (EC $4.17 \times 10^{-4} \mathrm{~S} \mathrm{~m}^{-1}$, $\mathrm{pH}$ 7.2) and was applied to the soil surface using a hand sprayer. The untreated check $(\mathrm{CK})$ was also prepared with

Table 1 Chemical properties of soil and treatments

\begin{tabular}{|c|c|c|c|c|c|c|c|c|c|c|}
\hline \multirow[t]{2}{*}{ Treatments } & \multirow[t]{2}{*}{$\mathrm{pH}$} & \multirow[t]{2}{*}{$\mathrm{EC}^{\dagger}$} & \multirow[t]{2}{*}{$\mathrm{OM}^{\ddagger}$} & \multirow[t]{2}{*}{ Avail. P } & \multirow[t]{2}{*}{$\mathrm{NH}_{4}^{+}-\mathrm{N}$} & \multirow[t]{2}{*}{$\mathrm{NO}_{3}-\mathrm{N}$} & \multicolumn{4}{|c|}{ Exchangeable cations } \\
\hline & & & & & & & $\mathrm{Ca}^{2+}$ & $\mathrm{K}^{+}$ & $\mathrm{Mg}^{2+}$ & $\mathrm{Na}^{+}$ \\
\hline & & $\mathrm{dS} \mathrm{m}^{-1}$ & $\%$ & & $\mathrm{mg} \mathrm{kg}^{-1}$ & & \multicolumn{4}{|c|}{$\mathrm{cmol} \mathrm{kg}^{-1}$} \\
\hline CK & $7.1 \mathrm{a}$ & $0.021 \mathrm{~ns}^{\S}$ & $2.2 \mathrm{c}$ & 1129 ns & 139 ns & $20.4 \mathrm{~b}$ & $4.3 \mathrm{~ns}$ & $0.3 \mathrm{a}$ & $1.3 \mathrm{a}$ & $0.1 \mathrm{a}$ \\
\hline PAM & $7.0 \mathrm{ab}$ & 0.022 ns & $3.1 \mathrm{~b}$ & 1349 ns & $95 \mathrm{~ns}$ & $20.9 b$ & $4.0 \mathrm{~ns}$ & $0.1 \mathrm{c}$ & $0.9 \mathrm{~b}$ & $0.1 \mathrm{a}$ \\
\hline $\mathrm{BP}$ & $6.9 \mathrm{~b}$ & $0.031 \mathrm{~ns}$ & $3.3 \mathrm{a}$ & 1226 ns & $106 \mathrm{~ns}$ & 31.9 a & $4.1 \mathrm{~ns}$ & $0.2 \mathrm{~b}$ & $1.0 \mathrm{~b}$ & $0.1 \mathrm{a}$ \\
\hline
\end{tabular}

The same letters in table indicate no difference determined by the Tukey's HSD test at a significance level of $0.05(n=3)$.

${ }^{+}$Electrical conductivity.

₹ Organic matter.

$\S$ Not significant. 
the same amount of distilled water five days before each experimental run.

Simulated rainfall with intensity of $20 \mathrm{~mm} \mathrm{~h}^{-1}$ was applied for $100 \mathrm{~min}$ to each treated soil test bed with a slope of $36 \%$. The total N (TN) and total P (TP) in runoff were analyzed by the ascorbic acid reduction method, namely the Standard Methods for the Examination of Water \& Wastewater (APHA 1995), using an ultraviolet absorption spectrophotometer (UV-1800, Shimadzu, Japan). Suspended solid (SS) in runoff was weighted by the glassfiber-filter-paper method (APHA 1995) and the turbidity was determined by a turbidimeter (2100P Turbidimeter, $\mathrm{HACH}, \mathrm{USA}$ ). A scanning electron microscopy (SEM; S-4300, Hitachi, Japan) were employed to scan the morphological characteristics of soil particles from soil test beds with/without treatments. The characteristics of runoff were determined in triplicate.

\section{Seed germination experiment}

A seed germination test was conducted in five replicates to examine the toxicity of PAM and BP to Chinese cabbage (Brassica campestris L.). Chinese cabbage seeds were washed twice using sterilized distilledwater and were also surface-sterilized with $1 \%$ sodium hypochlorite $(\mathrm{NaClO})$ for $15 \mathrm{~min}$. Each of 20 seeds was placed in a Petri dish and then the PAM and BP solutions at the concentrations of 0.05 and $0.1 \%$ were applied to moist filter papers in sterilized Petri dishes. The same amount of distilled water was also applied as CK. Three replicates were employed. During germination test, the incubation temperature was maintained at $25 \pm 2^{\circ} \mathrm{C}$ (ISTA 1996; Kim et al. 2010).

\section{Pot experiment}

The pot experiment was carried out in a glass-topped shelter house located at the Gangwondo Agricultural Research and Extension Services, Chuncheon-si, Gangwon province, Korea (37 $56^{\prime} 13^{\prime \prime} \mathrm{N}$ lat., $127^{\circ} 47^{\prime} 08^{\prime \prime} \mathrm{E}$ long.). Soil was packed into a Wagner's pot with a size of $1 / 5,000$ a and Chinese cabbage seedlings (30 d after germination) were transplanted into the pots. To avoid any nutrient effect, conventional fertilizers ( $\mathrm{N}, \mathrm{P}$, and $\mathrm{K}$ ) were evenly applied based on the RDA-NAAS recommendation (RDA-NAAS 2006). As mentioned before, the same amount of PAM and BP solutions were applied to the respective test pots. Chinese cabbage plants were sampled after $56 \mathrm{~d}$. Dry weight after $48 \mathrm{~h}$ at $70^{\circ} \mathrm{C}$, leaf length, leaf width, number of leaves, and chlorophyll concentration (in SPAD value; SPAD 502 Meter, Minolta, Japan) were determined.

\section{Statistics}

Data was analyzed using one-way analysis of variance (ANOVA) with dependent variables of germination rate, growth indices including leaf length, leaf width, number of leaves, dry weight, SPAD value, and soil properties. Differences in amendment means were compared using Tukey's honestly significant difference (HSD) test at a significance level of 0.05 (SAS 2003).

\section{Results and discussion}

\section{Anionic polyacrylamide (PAM) and biopolymer (BP)}

To ensure changes in soil aggregates and pore characteristics in soil treated with PAM, the SEM images were produced from $200 \mathrm{~kg} \mathrm{ha}^{-1}$ PAM-treated and untreated soils (Figure 1a,b). Images clearly showed that PAM addition stabilized soil structure and enhanced pore continuity. Similarly, Entry et al. (2002) and Sojka et al. (2005) used SEM images to report strand-like PAM binding to soil particles and concluded that PAM stabilizes the soil-surface structure and improves pore continuity in the soils.

The functional groups of the BP were analyzed at a wavelength range between 500 and 4,000 $\mathrm{cm}^{-1}$ using FT-IR spectroscopy (data not shown). Peaks at 1,558.54 and $1,401.05 \mathrm{~cm}^{-1}$ were assigned as ester groups $\left(-\mathrm{COO}^{-}\right)$, and a peak at $1,653.64 \mathrm{~cm}^{-1}$ indicated a carboxyl group $(\mathrm{C}=\mathrm{O})$. These findings supported the idea of Liu et al. (2008) that these functional groups may improve soil aggregates with strong interactions between soil particles and BP molecules, thereby reducing soil loss. Our results were similar to their findings that the peaks of the ester and carboxyl groups were detected at 1,560 and $1,410 \mathrm{~cm}^{-1}$, and at 1,680 and $1,450 \mathrm{~cm}^{-1}$, respectively.

\section{Changes of chemical properties in soils}

Application of BP decreased soil $\mathrm{pH}$ compared to the untreated loamy sand or the CK $(P<0.05$; Table 1$)$; however, no difference in $\mathrm{pH}$ was found between the CK and PAM-treated soil. When PAM or BP is applied to the soil, the acrylic acid units would be anionic when the soil is above pH 6 (Halverson and Panzer 1980; Sojka et al. 2007). Generally, these polymeric treatments decrease soil $\mathrm{pH}$ when initial soil $\mathrm{pH}>6$ because of the difficulty for anionic sites to be protonated and soil buffering capacity. No treatment effects on EC were found in treated soils. The soil OM contents in soils treated with PAM and BP were increased by 29.0 and $33.3 \%$, respectively, compared to the CK ( $P<0.05$ for all cases). This phenomenon can be explained with the OM holding capacity of polymers having strong interactions between soil particles and polymer's molecules in the soil aggregates during rainfall event. This finding agreed with studies of Dzhanpelsov et al. (1984) and Sojka et al. (2007) showing the improvements of soil physical properties and the stabilization of organic fractions in the soil when PAM were applied. Application of BP also likely increased soil $\mathrm{OM}$ and nitrate $\left(\mathrm{NO}_{3}-\mathrm{N}\right)$ in the soil as 

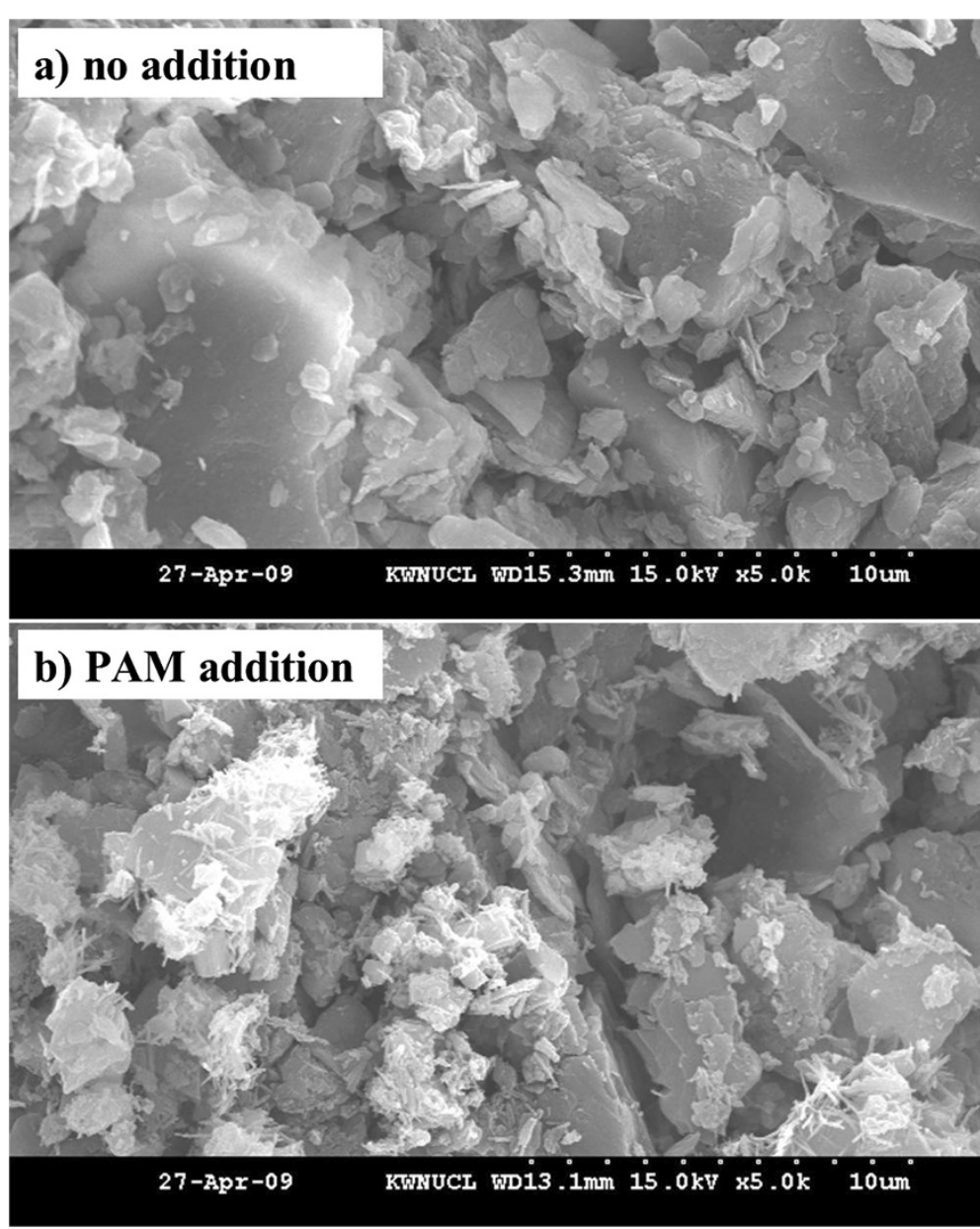

Figure 1 Scanning electron microscopy (SEM) images: a) no addition and b) $200 \mathrm{~kg} \mathrm{ha}^{-1}$ PAM addition.

compared to the CK because it contains lignin and starch.

\section{Changes of chemical properties in runoff}

The values of $\mathrm{pH}$ and EC in runoff from soils treated with PAM and BP did not differ with those from untreated soil or CK $(P>0.05$; Table 2$)$. Our findings revealed that both the PAM and BP applications would not harm the environment because the $\mathrm{pH}$ and $\mathrm{EC}$ values were within the safety criteria for normal water $\mathrm{pH}(6.05$ to 8.50$)$ and normal EC values $\left(<0.1 \mathrm{~S} \mathrm{~m}^{-1}\right.$ in rivers and lakes) (WHO 2008). Shainberg et al. (1990), and Lentz and Sojka (2009) reported an increase in EC when PAM was applied to irrigation water. We partially agree with their findings and insist that the applications of PAM and BP may increase EC, but these are negligible.

With the PAM treatment, TN value in runoff increased by 17.6 and $16.7 \%$ when compared to the CK and $\mathrm{BP}$, respectively (both $P<0.05$ ); however, no difference in TN was found between the CK and BP. Our findings agree with previous studies suggesting that nutrient loss from BP-treated soil to aquatic ecosystems may be smaller than the soil treated with the same rate of PAM, thereby reducing the potential for eutrophication that is caused by inflow of nutrients or agricultural chemicals due to runoff and soil erosion (Lentz et al. 1998; USEPA 2004; Sojka et al. 2007). Results also showed that a large amount $\left(200 \mathrm{~kg} \mathrm{ha}^{-1}\right)$ of PAM and

Table 2 Characteristics of runoff from soils treated/ untreated with PAM and BP at each rate of $200 \mathrm{~kg} \mathrm{ha}^{-1}$

\begin{tabular}{ccccccc}
\hline Texture & $\mathbf{p H}$ & $\mathbf{E C}^{\dagger}$ & $\mathbf{T N}^{\ddagger}$ & TP $^{\S}$ & SS $^{\text {q }}$ & Turbidity \\
\hline & & $10^{-4} \mathrm{~S} \mathrm{~m}^{-1}$ & & $\mathrm{mg} \mathrm{L}^{-1}$ & & NTU \\
CK & $6.87 \mathrm{ab}$ & $0.060 \mathrm{a}$ & $2.714 \mathrm{~b}$ & $0.118 \mathrm{ab}$ & $9647 \mathrm{a}$ & $412.0 \mathrm{a}$ \\
PAM & $6.93 \mathrm{~b}$ & $0.069 \mathrm{a}$ & $3.291 \mathrm{a}$ & $0.136 \mathrm{a}$ & $210.7 \mathrm{~b}$ & $13.2 \mathrm{~b}$ \\
BP & $6.64 \mathrm{a}$ & $0.075 \mathrm{a}$ & $2.740 \mathrm{~b}$ & $0.090 \mathrm{~b}$ & $429.2 \mathrm{~b}$ & $14.8 \mathrm{~b}$
\end{tabular}

The same letters in table indicate no difference determined by the Tukey's HSD test at a significance level of $0.05(n=3)$.

${ }^{\dagger}$ Electrical conductivity.

₹ Total nitrogen.

$\S$ Total phosphorus.

" Suspended soil. 
BP applications may not influence surrounding ecosystems regarding to TN and TP concentrations. For the effects of PAM application on nutrient loss from soils, many studies showed that the surface application of PAM reduced nutrient loss because of reductions in runoff and soil loss (Wallace and Wallace 1986; Lentz and Sojka 1994, Lentz and Bjomeberg 2001; Entry and Sojka 2003; Sojka et al. 2005). Lentz and Sojka (1994) found that losses in $\mathrm{N}$ and $\mathrm{P}$ from topsoil were reduced by 83 and $84 \%$, respectively, in response to the addition of PAM to the irrigation water. In this study, however, a higher TN concentration in runoff with the PAM was observed compared to BP. It may be explained with a higher $\mathrm{N}$ content of PAM (16.2\%) compared to the BP (5.3\%). Similarly, Kay-Shoemake et al. (1998) showed that PAM-treated soil contained significantly higher concentrations of $\mathrm{NO}_{3}$ and $\mathrm{NH}_{3}$ than the untreated potato field.

The amounts of TP in runoff from soils treated with PAM and BP were similar to the CK (each $P>0.05$ ). However, with comparison in PAM and BP, the amount of TP in runoff from soil treated with BP was $28.6 \%$ lower than that with PAM. Both applications of PAM and BP treatments are satisfied with a safety level of TP in runoff, suggesting no detrimental effect on the environment. A higher level of PAM application, $200 \mathrm{~kg} \mathrm{ha}^{-1}$ used in this study, may not deteriorate water quality and maintain the safety criteria of drinking water. We partially agree with a study of Lentz et al. (1998) that showed soluble P was reduced by $50 \%$ in Idaho's Snake River Valley when PAM was applied. Goodson et al. (2006) also found that PAM application at concentrations of $1 \mathrm{mg} \mathrm{L}^{-1}$ and $10 \mathrm{mg} \mathrm{L}^{-1}$ reduced particulate $\mathrm{P}$ in tail water by 31 and $78 \%$, respectively, and the higher level of PAM application significantly reduced TP compared to lower levels of PAM application or no amendment. Additionally, they mentioned that a reduction in soluble P depends on water salinity.

The suspended soil (SS) in runoff from soils treated/ untreated with PAM and BP were determined. No difference in SS was found between PAM and BP $(P>0.05)$. Average SS values from the soils treated with PAM and BP were decreased by $96.0 \%$ compared to the CK $(P<$ 0.05). We found that both applications of PAM and BP similarly increased soil stability and shear strength by clay flocculation between soil particles and molecules of these treatments. We suggest that the use of BP can be an environmentally friendly alternative to PAM that has extensively researched as a soil amendment (Theng 1982; Wallace and Wallace 1996; Zhang et al. 1998; 2006; Tang et al. 2006). Orts et al. (2000) showed that the BP suspension made from microfibrils of cellulose, starch xanthate, chitosan, and acid-hydrolyzed cellulose microfibril, reduced soil sediment by an average of $80 \%$ compared to the CK. Application of the BP treatment should be practically used to not only reduce raindrop impacts such as soil-surface seal formation, soil detachment, and degradation of water quality, but also reproduce industrial wastes (Levin et al. 1991; Orts et al. 1999, 2000, 2007; Lee et al. 2008; Liu et al. 2008).

The turbidity was significantly decreased in response to PAM and BP applications compared to the CK $(P<$ $0.05)$. No difference in turbidity was found between PAM and BP applications into soils. However, the average turbidity with these treatments was 99.9\% lower than the CK. Our findings agree with studies showing that polymeric soil amendments improve water permeability and interfere with detachment of soil particles, thereby stabilizing soil aggregates and structures (Deery et al. 2002; Entry et al. 2002; Al-Abed et al. 2003; Goodson et al. 2006; Orts et al. 2007; Sojka et al. 2007). Al-Abed et al. (2003) found that turbidity was reduced by an average of $60 \%$ with PAM treatment at concentrations of 5, 10, and $20 \mathrm{mg} \mathrm{L}^{-1}$. Goodson et al. (2006) similarly revealed that PAM applications at concentrations of 1,5 , and $10 \mathrm{mg} \mathrm{L}^{-1}$ produced significant reductions in irrigation water turbidity by 73,82 , and $98 \%$, respectively. From significant reductions in turbidity using PAM and BP, we suggest that the use of polymeric soil amendments on sloping non-vegetative or bare sites such as agricultural highland areas after harvesting effectively reduces runoff and soil loss, allowing decreasing nutrient loss increasing crop productivity.

\section{Aggregate stability and water holding capacity}

Aggregate stability was increased by 25.4 and $27.1 \%$ for soils treated with PAM and BP, respectively $(P<0.05$; Figure 2a), compared to the CK. An increase of aggregate stability in soil treated with $\mathrm{BP}$ was $2.2 \%$ higher than in soil treated with PAM, but was not significant. We found several possible reasons from previous studies indicating that the applications of PAM and BP induce clay flocculation in presence of $\mathrm{Ca}^{2+}$ which shrinks the electrical double layer and bridges PAM molecules and soil particles, thereby stabilizing soil aggregate structure (Wallace and Wallace 1996; Orts et al. 2000; Sojka et al. 2007).

For soils treated with PAM and BP, the water holding capacity was increased by an average of $32.6 \%$ compared to the CK (Figure 2b). Application of PAM has been found to effectively increase water permeability due to increased porosity and soil aggregation (Bouranis 1998; Kim et al. 1998). Other physical parameters such as water infiltration and retention, aeration, water drainage, and resistance to soil compaction and crusting may be increased in the soils treated with polymers (Cook and Nelson 1986; Zhang et al. 1998; Lee et al. 2008). 


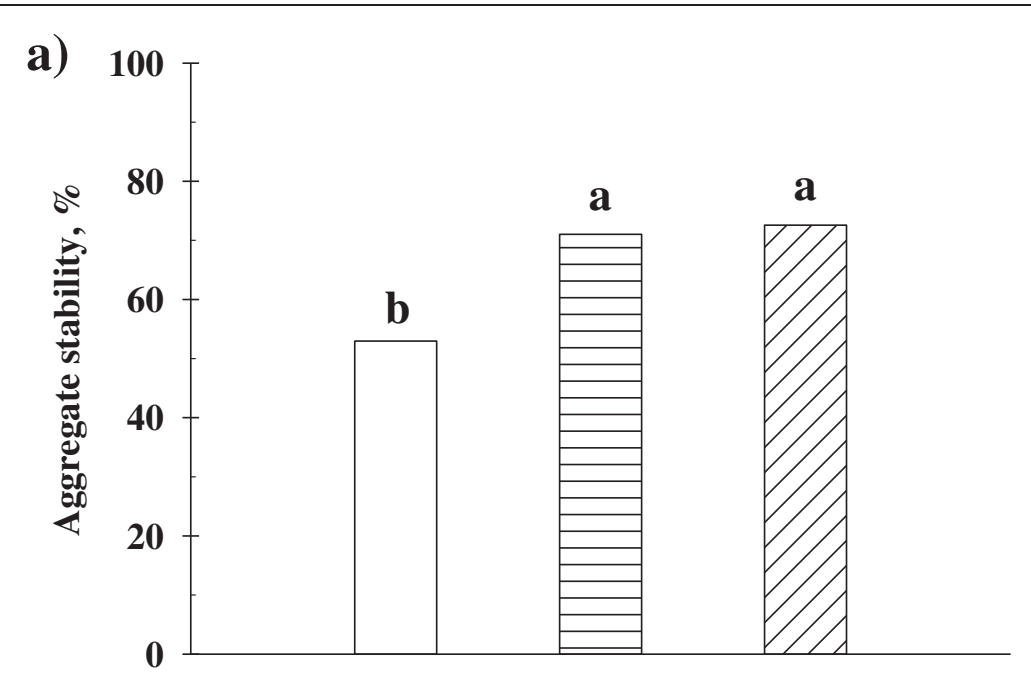

b)

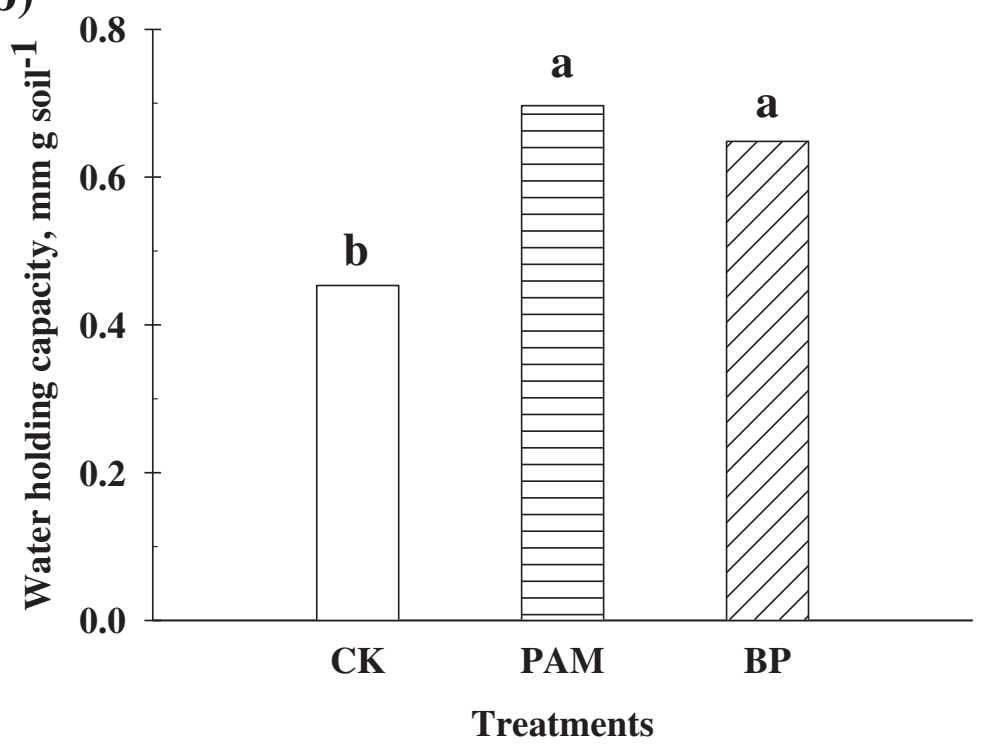

Figure 2 a) Soil stability and b) water holding capacity $(n=5)$.

\section{Germination test for Chinese cabbage}

Germination test was done to evaluate toxicity of PAM and BP treatment at each $0.1 \%$ rate for three days. After one day incubation, the germination rate was increased by an average of $13.6 \%$ in the Petri dishes treated with $0.1 \%$ PAM and BP compared to the CK $(P<0.05$ in both cases; Figure 3).

After two days incubation, no difference in germination rate was found between $\mathrm{BP}$ and $\mathrm{CK}$, but the germination rate with PAM treatment was $4.1 \%$ higher than others $(P>0.05)$. We conducted the same germination test with a lower concentration of PAM and BP at $0.05 \%$; however, it did not show any difference with the CK (data not shown). There were also no differences among treatments after three days incubation $(P>0.05)$. We did not observe any negative effect of PAM and BP applications on the germination of Chinese cabbage. The similar results have been reported by Wallace and Wallace (1986) who evaluated the effects of PAM on the germination of tomato, cotton, and lettuce. Rawitz and Hazan (1978) also mentioned that PAM application has no toxicity or no negative effects on germination.

\section{Growth test for Chinese cabbage}

Representative growth parameters for Chinese cabbage were produced as shown in Table 3. The values of leaf length from soils treated with PAM and BP were 8.0 and $11.3 \%$ higher than the CK, respectively, and those of leaf width were also 11.1 and $16.7 \%$ higher than the CK, respectively $(P<0.05$ for both cases). However, no treatment effect on leaf number and chlorophyll content (in SPAD unit) was found. More importantly, the average 


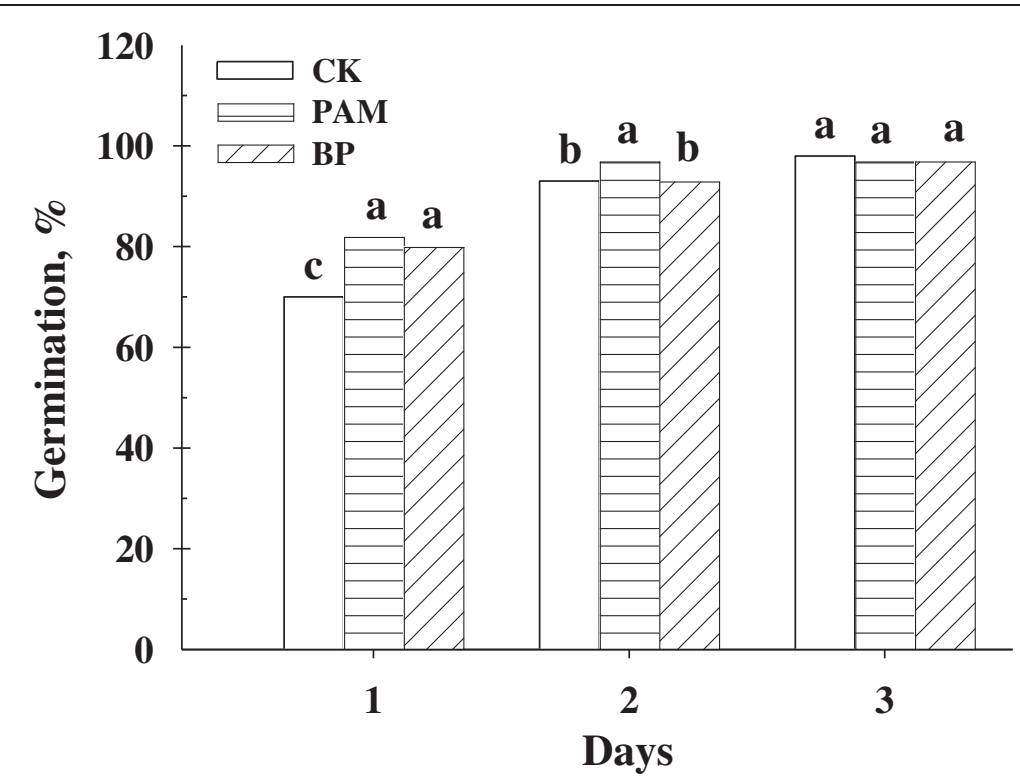

Figure 3 Germination rate of Chinese cabbage with PAM and BP at $0.1 \%$ concentration, along with the CK. The same letters above each bar indicate no difference between treatments determined by the Tukey's HSD test at a significance level of $0.05(n=5)$.

value of dry weight from soils treated with PAM and BP was increased by $17.7 \%$ compared to the CK $(P<0.05)$. These findings confirmed the results from a large number of studies (Baasiri et al. 1986; Toyama et al. 1984; Woodhouse and Johnson 1991; Letey et al. 1992; Kim et al. 1998). Application of polymeric soil amendments commonly causes increasing plant growth due to improvement of soil physical properties, most likely related to water retention and plant-available water. It should be noted that many considerations including application rate, type of polymer, plant species, and soil types need to be addressed for crop productivity.

\section{Conclusions}

This study was done to evaluate the effectiveness of commercially available PAM and synthesized BP originated from lignin, starch, acrylamide, and acrylic acid on soil erosion control, toxicity to plant and surrounding

Table 3 Leaf growth including number, length and width, SPAD readings, and dry weight of Chinese cabbage in loamy sand soils treated with PAM and BP at $200 \mathrm{~kg} \mathrm{ha}^{-1}$, along with the CK

\begin{tabular}{|c|c|c|c|c|c|}
\hline Treatment & & & & SPAD & Dry weight \\
\hline & Number & Length & Width & & g \\
\hline \multicolumn{6}{|c|}{$\mathrm{cm}$} \\
\hline CK & $33.3 \mathrm{~ns}^{\dagger}$ & $19.6 \mathrm{~b}$ & $12.0 \mathrm{~b}$ & $42.4 \mathrm{~ns}$ & $33.2 \mathrm{~b}$ \\
\hline PAM & $35.8 \mathrm{~ns}$ & $21.3 \mathrm{a}$ & $13.5 \mathrm{a}$ & $44.3 \mathrm{~ns}$ & $37.8 \mathrm{ab}$ \\
\hline $\mathrm{BP}$ & $35.8 \mathrm{~ns}$ & $22.1 \mathrm{a}$ & $14.4 \mathrm{a}$ & $45.6 \mathrm{~ns}$ & $42.9 \mathrm{a}$ \\
\hline
\end{tabular}

The same letters in table indicate no difference determined by the Tukey's HSD test at a significance level of $0.05(n=3)$.

${ }^{\dagger}$ Not significant. environments, and plant growth. Based on results from this study, the applications of PAM and BP do not have any negative effect. Partially, the synthesized BP treatment may be better for reducing nutrient loss from soils compared to commercial PAM. The aggregate stability was increased by 25.4 and $27.1 \%$ for soils treated with PAM and BP, respectively, compared to the CK. Moreover, the values of SS and turbidity were significantly reduced by up to 96.0 and $99.9 \%$, respectively, compared to the CK. Moreover, the application of polymers didn't show any negative effect or toxicity through seed germination or plant growth. The use of polymeric soil amendments may be an effective way to mitigate the current problems of soil erosion and nonpoint source pollution that we faced. In addition, the further research on BP synthesis using waste materials would be beneficial in the future.

\section{Competing interests}

The authors declare that they have no competing interests.

\section{Authors' contributions}

SSL carried out the experiment and drafted the manuscript under the supervision of Professor YSO. SXC and Y-YC helped to draft the manuscript and reviewed the manuscript. All authors read and approved the final manuscript.

\section{Acknowledgements}

This research was supported by the "Cooperative Research Program for Agriculture Science \& Technology Development (Project No. PJ9070882012)" of the Rural Development Administration and the Korea Ministry of Environment as "The GAIA project (No.173-111-040)" in Korea.

Author details

'Department of Biological Environment, Kangwon National University, Chuncheon 200-701, Korea. ${ }^{2}$ Department of Renewable Resources, University of Alberta, 442 Earth Sciences Building, Edmonton, AB T6G 2E3, Canada. 
${ }^{3}$ Department of Environmental Engineering, Kwangwoon University, Seoul 139-701, Korea.

Received: 17 July 2013 Accepted: 2 October 2013 Published: 17 October 2013

\section{References}

Agassi M, Ben-Hur M (1992) Stabilizing steep slopes with soil conditioners and plants. Soil Technol 5:249-256

Agassi M, Shainberg I, Morin J (1990) Slope, aspect, and phosphogypsum effects on runoff and erosion. Soil Sci Soc Am J 54:1102-1106

Ajwa HA, Trout TJ (2006) Polyacrylamide and water quality effects on infiltration in sandy loam soils. Soil Sci Soc Am J 70:643-650

Al-Abed N, Amayreh J, Shudifat E, Qaqish L, El-Mehaisin G (2003) Polyacrylamide (PAM) effect on irrigation induced soil erosion and infiltration. Arch Agron Soil Sci 49:301-308

APHA (1995) Standard methods for the examination of water and wastewater, 19th edn. American Public Health Association - American Water Works Association - Water Environment Federation, Baltimore, MD, USA

Baasiri M, Ryan J, Mucheik M, Harik SN (1986) Soil application of a hydrophilic conditioner in relation to moisture, irrigation frequency and crop growth. Commun Soil Sci Plant Anal 17:573-589

Bouranis DL (1998) Designing synthetic soil conditioners via postpolymerization reactions. In: Wallace A, Terry RE (eds) Handbook of Soil Conditioners: Substances that Chance the Physical Properties of Soil. Marcel Dekker Inc., New York, NY, USA, pp 333-360

Bradford JM, Foster GR (1996) Interrill soil erosion and slope steepness factors. Soil Sci Soc Am J 60:909-915

Bremner JM (1996) Nitrogen. In: Sparks DL et al (eds) Methods of Soil Analysis, Part 3 - Chemical Methods. Am Soc Agron-Soil Sci Soc Am Inc., Madison, WI, USA, pp 1085-1116

Chan KY, Sivapragasam S (1996) Amelioration of a degraded hardsetting soil using an anionic polymeric conditioner. Soil Technol 9:91-100

Choi JD, Park JS, Kim JJ, Yang JE, Jung YS, Yun SY (2000) Soil quality assessment for environmentally sound agriculture in the mountainous soils- Analysis of sediment data and suggestion of best management practices. Korean J Environ Agric 19:201-205

Clark EH, Haverkamp JA, Chapman W (1985) Eroding soils: the off-farm impacts. Conservation Foundation, Washington, DC, USA

Cook DF, Nelson SD (1986) Effect of polyacrylamide on seedling emergence in crust-forming soils. Soil Sci 141:328-333

Deery D, Sivapalan S, Chan KY (2002) Effect of polyacrylamides and gypsum on turbidity of water. In: Proceedings of the ASSSI Future Soils Conference. Perth, Western Australia, Australia, pp 52-53, 2-6 December

Dzhanpelsov RD, Popova NS, Akkulova ZG, Kricheskiy LA, Sokolova TM, Marchenko AY, Ramazanova AR (1984) Study of new polymeric soil conditioners based on the humic acid of coal. Soviet Soil Sci 16:83-89

Entry JA, Sojka RE (2003) The efficacy of polyacrylamide to reduce nutrient movement from an irrigated field. Trans ASAE 46:75-83

Entry JA, Sojka RE, Watwood M, Ross C (2002) Polyacrylamide preparations for protection of water quality threatened by agricultural runoff contaminants. Environ Poll 120:191-200

Flanagan DC, Norton LD, Shainberg I (1997) Effect of water chemistry and soil amendments on a silt loam soil, Part I. Infiltration and Runoff. Trans ASAE 40:1549-1554

Fox DM, Bryan RB (1999) The relationship of soil loss by interrill erosion to slope gradient. Catena 38:211-222

Fuller LG, Goh TB, Oscarson DW, Biliaderis CG (1995) Flocculation and coagulation of $\mathrm{Ca}$ - and $\mathrm{Mg}$-saturated montmorillonite in the presence of a neutral polysaccharide. Clays Clay Miner 43:533-539

Gantzer CJ, Anderson SH, Thompson AL (1990) Estimating soil erosion after 100 years of soil and crop management on Sanborn Field. J Soil Water Conserv 45:641-644

Gerits J (1990) Wind action in relation to overland flow and water erosion. Catena suppl 17:67-78

Ghehsareh MG, Khosh-Khui M, Abedi-Koupai J (2010) Effects of superabsorbent polymer on water requirement and growth indices of Ficus benjamina $\mathrm{L}$. 'STARLIGHT'. J Plant Nutr 33:785-795

Goodson CC, Schwartz G, Amrhein C (2006) Controlling tailwater sediment and phosphorus concentrations with polyacrylamide in the Imperial Valley, California. J Environ Qual 35:1072-1077
Halverson F, Panzer HP (1980) Flocculating agents. In: Kirk I, Othmer DF (eds) Encyclopedia of Chemical Technology. John Wiley \& Sons, Inc., New York, NY, USA, pp 489-523

Heo S, Jun MS, Park S, Kim KS, Kang SK, Ok YS, Lim KJ (2008) Analysis of soil erosion reduction ratio with changes in soil reconditioning amount for highland agricultural crops. Korean Soc Water Qual 24:185-194

Hüttermann A, Zommorodi M, Reise K (1999) Addition of hydrogels to soil for prolonging the survival of Pinus halepensis seedlings subjected to drought. Soil Tillage Res 50:295-304

ISTA (1996) International rules for seed testing. In: Seed Science and Technology, vol 24. International Seed Testing Association, Bassersdorf, Switzerland, p 336

Johnson MS (1984a) Effects of gel-forming polyacrylamides on moisture storage in sandy soils. J Sci Food Agric 35:1196-1200

Johnson MS (1984b) Effects of soluble salts on water absorption by gel-forming soil conditioners. J Sci Food Agric 35:1063-1066

Jung KH, Sonn YK, Hong SY, Hur SO, Ha SK (2005) Assessment of national soil loss and potential erosion area using the digital detailed soil maps. Korean $J$ Soil Sci Fert 38:59-65

Kay-shoemake J, Watwood ME, Lentz RD, Sojka RE (1998) Polyacrylamide as an organic nitrogen source for soil microorganisms with potential effects on inorganic soil nitrogen in agricultural soil. Soil Biol Biochem 30:1045-1052

Kim SK, Saneyuki K, Ryozo S (1998) Effects of potassium-cyanoethylstarch (K-CES) and polyacrylamide (PAM) on growth of spinach (Spinacia oleracea L.). Korean J Hort Sci Technol 16:226-228

Kim SC, Yang JE, Ok YS, Skousen J, Kim DG, Joo JH (2010) Accelerated metolachlor degradation in soil by zerovalent iron and compost amendments. Bull Environ Contam Toxicol 84:459-464

Kinnell PIA (2000) The effect of slope length on sediment concentrations associated with side-slope erosion. Soil Sci Soc Am J 64:1004-1008

Kuo S (1996) Phosphorous. In: Sparks DL et al (eds) Methods of Soil Analysis Part 3 - Chemical Methods. Am Soc Agron-Soil Sci Soc Am Inc., Madison, WI, USA, pp 869-920

Lee SS, Gantzer CJ, Thompson AL, Anderson SH, Ketcham RA (2008) Using highresolution computed tomography analysis to characterize soil-surface seals. Soil Sci Soc Am J 72:1478-1485

Lee SS, Gantzer CJ, Thompson AL, Anderson SH (2011) Polyacrylamide efficacy for reducing soil erosion and runoff as influenced by slope. J Soil Water Conserv 66:172-177

Lentz RD, Bjomeberg DL (2001) PAM and straw residue effects on irrigation furrow erosion and infiltration. In: Proceedings of the International Symposium: Soil Erosion Research for the 21st Century. January 3-5. ASAE pub 701P0007, Honolulu, Hawaii, USA, pp 175-178

Lentz RD, Sojka RE (1994) Field results using polyacrylamide to manage furrow erosion and infiltration. Soil Sci 158:274-282

Lentz RD, Sojka RE (2009) Long-term polyacrylamide formulation effects on soil erosion, water infiltration, and yields of furrow-irrigated crops. Agron J 101:305-314

Lentz RD, Sojka RE, Robbins CW (1998) Reducing phosphorus losses from surfaceirrigated fields: Emerging polyacrylamide technology. J Environ Qual 27:305-312

Lentz RD, Sojka RE, Makey BE (2002) Fate and efficacy of polyacrylamide applied in furrow irrigation: Full-advance and continuous treatments. J Environ Qual 31:661-670

Letey J, Clark PR, Amrhein C (1992) Water-sorbing polymers do not conserve water. California Agric 46:9-10

Levin J, Ben-Hur M, Gal M, Levy GJ (1991) Rain energy and soil amendments effects on infiltration and erosion of three different soil types. Aust J Soil Res 29:455-465

Liu C, Wu G, Mu H, Yuan Z, Tang L, Lin X (2008) Synthesis and application of lignin-based copolymer LSAA on controlling non-point source pollution resulted from surface runoff. J Environ Sci 20:820-826

McElhiney M, Osterli P (1996) An integrated approach for water quality: The PAM connection-West Stanislaus HUA, CA. In: Sojka RE, Lentz RD (eds) Proceedings: Managing Irrigation Induced Erosion and Infiltration with Polyacrylamide. College of Southern Idaho, Twin Falls, ID, 6-8 May, University of Idaho, Twin Falls, Idaho, USA. Misc Pub No. 101-96, pp. 27-30

McIntyre DS (1958) Soil splash and the formation of surface crusts by raindrop impact. Soil Sci 85:261-266

Mikkelsen RL (1994) Using hydrophilic polymers to control nutrient release. Fert Res 38:53-59

Mitchell AR (1986) Polyacrylamide application in irrigation water to increase infiltration. Soil Sci 141:353-358 
Myers N (1993) Gaia: An Atlas of Planet Management. Anchor/Doubleday, Garden City, New York, USA

Nagle GN (2001) The contribution of agricultural erosion to reservoir sedimentation in the Dominican Republic. Water Policy 3:491-505

Nelson DW, Sommers LE (1996) Total carbon, organic carbon, and organic matter. In: Sparks DL et al (eds) Methods of Soil Analysis, Part 3 - Chemical Methods. Am Soc Agron-Soil Sci Soc Am Inc., Madison, Wisconsin, USA, pp 961-1010

Ok YS, Chang SX, Feng Y (2007) Sensitivity to acidification of forest soils in two contrasting watersheds in the oil sands region of Alberta. Pedosphere 17:747-757

Orts WJ, Sojka RE, Glenn GM, Gross RA (1999) Preventing soil erosion with polymer additives. Polymer News 24:406-413

Orts WJ, Sojka RE, Glenn GM, Gross RA (2000) Biopolymer additives for the reduction of soil erosion losses during irrigation. Ind Crops Prod 11:19-29

Orts WJ, Roa-Espinosa A, Sojka RE, Glenn GM, Imam SH, Erlacher K, Pedersen J (2007) Use of synthetic polymers and biopolymers for soil stabilization in agricultural, construction, and military applications. J Materials Civil Eng 19:58-66

Parker R, Ring SG (2005) The physical chemistry of starch. In: Dumitriu S (ed) Polysaccharides: Structural Diversity and Functional Versatility. Marcel Dekker, New York, USA, pp 591-604

Partab T (2004) Evolving sustainable production systems in sloping upland areas: land classification issues and options. Asian Productivity Organization, Tokyo, Japan, pp 1-221

Pimentel D, Harvey C, Resosudarmo P, Sinclair K, Kurz D, McNair M, Crist S, Shpritz L, Fitton L, Saffouri R, Blair R (1995) Environmental and economic costs of soil erosion and conservation benefits. Sci 267:1117-1123

Polyakov V, Lal R (2004) Modeling soil organic matter dynamics as affected by soil water erosion. Environ Int 30:547-556

Quastel JH (1952) Influence of organic matter on aeration and structure of soil. Soil Sci 73:419-426

Quastel JH (1954) Soil conditioners. Annu Rev Plant Physiol 5:75-92

Rawitz E, Hazan A (1978) The effect of stabilized, hydrophobic aggregate layer properties on soil water regime and seeding emergence. Soil Sci Soc Am J 42:787-793

RDA-NAAS (2006) Standard Application of Fertilizers for Plants. National Academy of Agricultural Science. Rural Development Administration, Suwon, Korea

RDA-NIAST (1988) Methods of Soil Chemical Analysis. National Institute of Agricultural Science and Technology. Rural Development Administration, Suwon, Korea

Roa-Espinosa A (1996) Screening of polymers to determine their potential use in erosion control on construction sites. In: Sojka RE, Lentz RD (eds) Proceedings of the Managing Irrigation-Induced Erosion and Infiltration with Polyacrylamide. Misc Pub 101-96. University of Idaho, Twin Falls, ID, USA, pp 77-83

Roa-Espinosa A, Bubenzer GD, Miyashita ES (1999) Sediment and runoff control on construction sites using four application methods of polyacrylamide mix. ASAE Paper No. 99-2013. Am Soc Agric Eng, St. Joseph, MI, USA

SAS (2003) he SAS system for Linux, Release 9.1. Statistical Analysis System Institute, Inc, Cary, North Carolina, USA

Sepaskhah AR, Bazrafshan-Jahromi AR (2006) Controlling runoff and erosion in sloping land with polyacrylamide under a rainfall simulator. Biosyst Eng 93:469-474

Shainberg I, Levy GJ (1994) Organic polymers and soil sealing in cultivated soil. Soil Sci 149:301-307

Shainberg I, Warrington DN, Rengasamy P (1990) Water quality and PAM interactions in reducing surface sealing. Soil Sci 149:301-307

Sharma J (2004) Establishment of perennials in hydrophilic polymer-amended soil. Southern Nursery Ass Res Conf 42:530-532

Sheldrick BH, Wang C (1993) Particle size distribution. In: Carter MR (ed) Soil Sampling and Methods of Analysis. Can Soc Soil Sci, Lewis Publishers, Boca Raton, Florida, USA, pp 499-511

Shin YK (2006) Policy direction for environmentally friendly reorganization of highland agriculture. Korean J Agric Manage Policy 33:519-536

Sivapalan S (2002) Potential use of polyacrylamides (PAM) in Australian irrigated agriculture. In: Sutton BG (ed) Proceedings Irrigation Australia 2002 Conference. , Sydney, New South Wales, Australia, pp 339-346

Sojka RE, Morishita DW, Foerster JA, Wille MJ (2003) Weed seed transport and weed establishment as affected by polyacrylamide in furrow-irrigated corn. J Soil Water Conserv 58:319-326
Sojka RE, Entry JA, Orts WJ, Morishita DW, Ross CW, Horne DJ (2005) Syntheticand bio-polymer use for runoff water quality management in irrigated agriculture. Water Sci Technol 51:107-115

Sojka RE, Entry JA, Furhmann JJ (2006) The influence of high application rates of polyacrylamide on microbial metabolic potential in an agricultural soil. Appl Soil Ecol 32:243-252

Sojka RE, Bjorneberg DL, Entry JA, Lentz RD, Orts WJ (2007) Polyacrylamide in agriculture and environmental land management. Adv Agron 92:75-162

Sumner ME, Miller WP (1996) Cation exchange capacity and exchange coefficients. In: Sparks DL et al (eds) Methods of Soil Analysis, Part 3 Chemical Methods. Am Soc Agron-Soil Sci Soc Am Inc., Madison, WI, USA, pp 1201-1230

Tang Z, Lei T, Yu J, Shainbegr I, Mamedov Al, Ben-Hur M, Levy GJ (2006) Runoff and interrill erosion in sodic soils treated with dry PAM and phosphogypsum. Soil Sci Soc Am J 70:679-690

Theng BKG (1982) Clay-polymer interactions: Summary and perspectives. Clays Clay Miner 30:1-10

Thompson AL, Gantzer CJ, Anderson SH (1991) Topsoil depth, fertility, water management, and weather influences on yield. Soil Sci Soc Am J 55:1085-1091

Toyama M, Takeuchi Y, Nakade Y, Sugimoto K (1984) Studies on afforestation in arid zone by utilization of water holding substances. 7. Effects on outdoor culture of vegetables [Allium chinensis, Chinese cabbage and Raphanus sativus]. Bull Sand Dune Res Inst 32:1-13

Troeh FR, Hobbs JA, Donahue RL (2004) Soil and Water Conservation for Productivity and Environmental Protection, 4th edn. Pearson Education, Upper Saddle River, NJ, USA

USEPA (2004) National Water Quality Inventory: Report to Congress. The United States Environmental Protection Agency. USA, Washington DC

Wallace A, Wallace GA (1986) Control of soil erosion by polymeric soil conditioners. Soil Sci 141:377-380

Wallace A, Wallace GA (1996) Need for solution or exchangeable calcium and/or critical EC level for flocculation of clay by polyacrylamides. In: Sojka RE, Lentz $\mathrm{RD}$ (eds) Proceedings of Managing Irrigation-induced Erosion and Infiltration with Polyacrylamide, May 6-8. Univ. of Idaho, Twin Falls, Idaho, USA, Misc Pub 101-96. pp. 59-63

WHO (2008) Guidelines for drinking-water quality, 3rd edn. World Health Organization, Geneva, Switzerland

Woodhouse J, Johnson MS (1991) Effect of superabsorbent polymers on survival and growth of crop seedlings. Agric Water Manage 20:63-70

WSDOT (2008) Polyacrylamide for soil erosion protection. In: WSDOT Highway Runoff Manual (M 31-16.01). The Washington State Department of Transportation, Olympia, Washington DC, USA, pp 5-6A

Yang JE, Skousen JG, Ok YS, Yoo KY, Kim HJ (2006) Reclamation of abandoned coal mine waste in Korea using lime cake by-product. Mine Water Environ 25:227-232

Yoon YM, Ok YS, Kim DY, Kim JG (2004) Agricultural recycling of the by-product concentrate of livestock wastewater treatment plant processed with VSEP RO and bio-ceramic SBR. Water Sci Technol 49:405-412

Zhang XC, Miller WP, Nearing MA, Norton LD (1998) Effects of surface treatment on surface sealing, runoff and interrill erosion. Trans Am Soc Agric Eng 41:989-994

\section{doi:10.1186/2193-1801-2-534}

Cite this article as: Lee et al:: Commercial versus synthesized polymers for soil erosion control and growth of Chinese cabbage. SpringerPlus 2013 2:534. 